\title{
Contaminants of Emerging Concern in African Wastewater Effluents: Occurrence, Impact and Removal Technologies
}

\author{
Mohamed Chaker Necibi ${ }^{1, *(D)}$, Driss Dhiba ${ }^{1}$ a and Souad El Hajjaji $^{2}(\mathbb{D}$ \\ 1 International Water Research Institute (IWRI), Mohammed VI Polytechnic University (UM6P), \\ Green City, Ben Guerir 43150, Morocco; driss.dhiba@um6p.ma \\ 2 Laboratory of Spectroscopy, Molecular Modeling, Materials, Nanomaterials, Water and \\ Environment, (LS3MN2E-CERNE2D), Faculty of Sciences, Mohammed V University in Rabat, \\ Av Ibn Battouta BP1014, Rabat 10106, Morocco; hajjajisouad@yahoo.fr \\ * Correspondence: chaker.necibi@um6p.ma
}

\section{check for}

updates

Citation: Necibi, M.C.; Dhiba, D.; El Hajjaji, S. Contaminants of Emerging Concern in African Wastewater Effluents: Occurrence, Impact and Removal Technologies. Sustainability 2021, 13, 1125. https:// doi.org/10.3390/su13031125

Received: 2 December 2020

Accepted: 12 January 2021

Published: 22 January 2021

Publisher's Note: MDPI stays neutral with regard to jurisdictional claims in published maps and institutional affiliations.

Copyright: (c) 2021 by the authors. Licensee MDPI, Basel, Switzerland. This article is an open access article distributed under the terms and conditions of the Creative Commons Attribution (CC BY) license (https:// creativecommons.org/licenses/by/ $4.0 /)$.

\begin{abstract}
Worldwide, the pollution of water bodies by contaminants of emerging concern (CECs) such as pharmaceuticals, endocrine disrupting compounds, flame retardants including brominated flame retardants (BFRs) and perfluorochemicals (PFCs), micro plastics, nanomaterials, and algal toxins, to name just a few, is creating a new set of challenges to the conventional wastewater treatment facilities, which demonstrate inefficiency in removing/degrading many CECs. As a consequence, environmentalists started to detect the presence of some of those contaminants at alarming levels in certain countries, with possible negative effects on aquatic species and often increased potential for human health risks through the exposure to the contaminated waters, or the reuse of treated wastewater in agriculture and household use. Such issues are more accentuated in the African continent due to various socio-economic problems giving rise to poor sanitation systems and serious shortages in wastewater treatment plants in many regions, making it difficult to tackle the problem of conventional pollutants, let alone to deal with the more challenging CECs. Thus, in order to effectively deal with this emerging environmental threat, African researchers are working to develop and optimize sound sampling and analytical procedures, risk assessment models, and efficient remediation technologies. In this review, related recent research efforts conducted in African universities and research institutions will be presented and discussed with respect to the occurrence and assessment of CECs in African wastewater effluents, the potential risks to aquatic ecosystems and humans, the tailored remediation techniques, along with some knowledge gaps and new research directions.
\end{abstract}

Keywords: emerging contaminants; wastewaters; Africa; occurrence; impacts; aquatic ecosystems; remediation

\section{Introduction}

Contaminants of emerging concern (CECs) are a cluster of chemical compounds newly identified by scientists as harmful substances to the environment and possibly to humans (through an inherent toxicity or a recalcitrant and persistent nature), but so far with no established regulatory guidelines for the majority of them [1,2].

In the last decades, CECs such as human and animal pharmaceuticals, endocrine disrupting compounds (EDCs), personal care products (PPCPs), microplastics, nanomaterials, and so on, are increasingly and globally causing environmental and public health concern. Consequently, numerous scientific studies have started, and actively continue, to be conducted all over the world, with proven reports on the pollution of aquatic ecosystems by CECs, and most notably pharmaceutical drugs and their derivates [3-5].

After assessing the occurrence of CECs in water bodies (lakes, rivers, etc.), most researchers traced back the origins of such pollution and proved that conventional and outdated wastewater treatment plants (WWTPs) were one of the main sources of pollution with CECs [6,7]. Indeed, many studies reported the inefficacy of the activated sludge-based WWTPs to treat such recalcitrant trace chemicals based on the monitored occurrence of 
selected CECs in WWTPs effluents and nearby water bodies [8,9]. Other studies also proved that even more advanced wastewater treatment technologies such the membrane bioreactor process were not able to remove all the CECs present in urban wastewaters $[10,11]$.

Then, research studies begun to be carried out to analyze the fate and ecotoxicology of many CECs in wastewater and aquatic environments [12,13]. In this regard, endocrine disrupting compounds (EDCs) are among the most investigated CECs. Indeed, their presence in the environment, raw sewage, treated sewage effluents, receiving rivers, and surface waters [14] constitute a serious menace due to the possible interference with normal function of the endocrine systems of wildlife and humans, directly through exposure or indirectly via the food chain [15].

Many CECs are being investigated including human and veterinary pharmaceuticals, disinfection by-products (DBPs), personal care products (PCPs), new pesticides, flame retardants, microplastics, algal toxins, and engineered nanomaterials. In this context, it has to be noticed that the majority of the related research studies are concentrated in North American, European and selected Asian countries, and that this topic is still absent in the majority of African countries and relatively new in a few of them, with most research studies still in the early stages of assessing the occurrence and, to a lesser extent, the fate of CECs in WWTPs and receiving water bodies [16].

After analyzing the threat of water pollution by CECs (i.e., occurrence, fate and impact), researchers in the water treatment field started to experiment with processes and technologies to tackle this issue. In this context, however, the high reactivity and mobility, and the very low concentrations, of most CECs posed a serious challenge to this R\&D effort, especially when coupled with the large volumes of the to-be-treated wastewater streams and water bodies.

To face such a set of challenges, and to keep the reclamation of waste water a viable and safe option for any sustainable water management strategy, scientific researchers hold the key to any efficient and sustainable solution to effectively treat wastewater from both conventional and emerging pollutants, and ultimately, to reclaim new water sources for the industrial and agricultural sectors, especially in African countries where the issue of CECs in wastewater is not yet gaining the proper attention it deserves due the various factors that the present review will analyze, and suggest some recommendations on in the final "Outlook" section.

Thus, this review will focus on the state-of-the-art knowledge on the occurrence, impact and treatment of CECs in African wastewater effluents, based primarily on research studies published between 2015 and 2020. First, the occurrence of CECs in the effluents on WWTPs in African countries will be analyzed. Then, studies focusing on assessing the impacts of CECs on the environment and human health will be presented and discussed. Regarding the removal of CECs from water media, several technologies and processes investigated by African researchers will be studied. In addition, the present review will identify knowledge gaps and propose new research directions.

\section{Occurrence of CECs in African Wastewater Effluents}

The global awareness about the detection and eco-toxicological effects of CECs in aquatic ecosystems incentivized African researchers to begin to investigate this novel environmental problem and its adverse effects on aquatic life, and animal and human health. The first step in such a complicated enterprise is to assess the current status regarding the occurrence of CECs in wastewater, sludge, surface water, sediment, groundwater and drinking water sources in various African countries.

In the present section, studies related to the assessment of the presence on CECs in wastewater effluents will be analyzed. Since WWTPs are among the main point sources for CECs contaminating aquatic environments, we will focus on African studies assessing the occurrence of CECs in the effluents of these wastewater treatment facilities. It has to be noted that a fraction of the CECs in African aquatic ecosystems (mainly pharmaceutical drugs) is being directly discharged with human excretion wastes into water streams. How- 
ever, due the obvious difficulties in assessing such "hidden inputs", the following analysis of related research studies will focus on the routinely monitored wastewater effluents.

In this regard, a PhD study was conducted in and around Cape Town, South Africa to assess the occurrence and quantify several CECs including six perfluorochemicals (PFCs), Bisphenol and Acetaminophen in WWTPs effluents [17]. The results published in 2016 revealed that among the wastewater samples taken for several WWTPs in the region, the studied CECs were identified in $90 \%$ of them. Bisphenol A was the most observed contaminant with the highest average concentration of $210 \pm 6.5 \mu \mathrm{g} / \mathrm{L}$ in one of the investigated WWTPs. Furthermore, high concentrations of selected PFCs (namely, perfluorooctanoic acid, perfluorononanoic acid, and perfluorooctane sulphonate (PFOS)) were detected in the tested effluents of some WWTPs which, according to the authors, can be caused by the desorption of PFCs from solids, matrix interference and degradation of PFCs precursors within the treatment plants. For instance, the average maximum concentration of PFOS in the Bellville WTTPs' effluent was $10.2 \mathrm{ng} / \mathrm{L}$.

Regarding the assessment of acetaminophen, the results showed that the average concentrations ranged between 27.9 and $175 \mu \mathrm{g} / \mathrm{L}$ in the WWTP influents, compared to $5.2 \mu \mathrm{g} / \mathrm{L}$ in its effluents. Hence, removal wise, the authors reported that the wastewater treatment processes were able to reduce the influent concentration of acetaminophen by $95.6-100 \%$, and that of bisphenol A and total PFCs by $86.5-99.7$ and $54.33-73.65 \%$, respectively, with better removal efficacies for WWTPs with tertiary treatment technology compared to plants with only secondary treatment processes.

Regarding the issue of pollution of African water resources caused by CECs discharged with WWTPs, few research studies were conducted on this important topic. Most of the related publications, although also few compared to published studies in other continents, focused on the occurrence of CECs in freshwater aquatic environments [18-20]. In this regard, aus der Beek et al. [21] conduced a worldwide bibliometric study on the topic of environmental occurrence of pharmaceutically active compounds. It was found that 23 publications were from Africa, compared to 730 from Europe and 143 from the USA.

In this same study, the authors presented a map highlighting the average number of pharmaceutical compounds detected in WWTP's inflows, effluents, and sewage sludge by country.

As shown in Figure 1, the research effort in African countries related to the detection of pharmaceuticals is very limited, even when compared developing countries in Asia and Latin America. In the continent itself, out of the 54 countries, just five managed to collect data on the occurrence of pharmaceutical drugs and their derivates in wastewaters (South Africa, Kenya, Cote d'Ivoire, Tunisia, and Zimbabwe). Thus, African research laboratories and institutions, public and private ones alike, need to give the issue of CECs the attention it really deserves. Simultaneously, governments and stakeholders need to allocate incentivizing funds to promote this research effort.

Antibiotics are also among the widely detected CECs in aquatic environments, and are often linked to the poor removal efficacies of WWTPS to remove them from wastewater. In this context, a study conducted in Tunisia detected the presence of antibiotics in roughly similar concentrations in both municipal WWTP influent and effluent, which proves the inability of biological treatments of water to effectively deal with antibiotics in WWTPs [22]. The related results for four wastewater treatment plants and five coasts in Tunisia revealed the presence of high concentrations of antibiotics ranging from 0.1 to $646 \mathrm{ng} / \mathrm{mL}$, which, according to the authors, can induce many negative impacts on health and the environment. It has to be highlighted that WWTPs are not the only "source" for CECs in lakes and rivers in Africa. Indeed, among the other potential factors that could contribute to the contamination of aquatic ecosystems in the continent, there is the human waste in the rural communities, which is often released directly into the environment, and is transferred into rivers through water run-offs. 


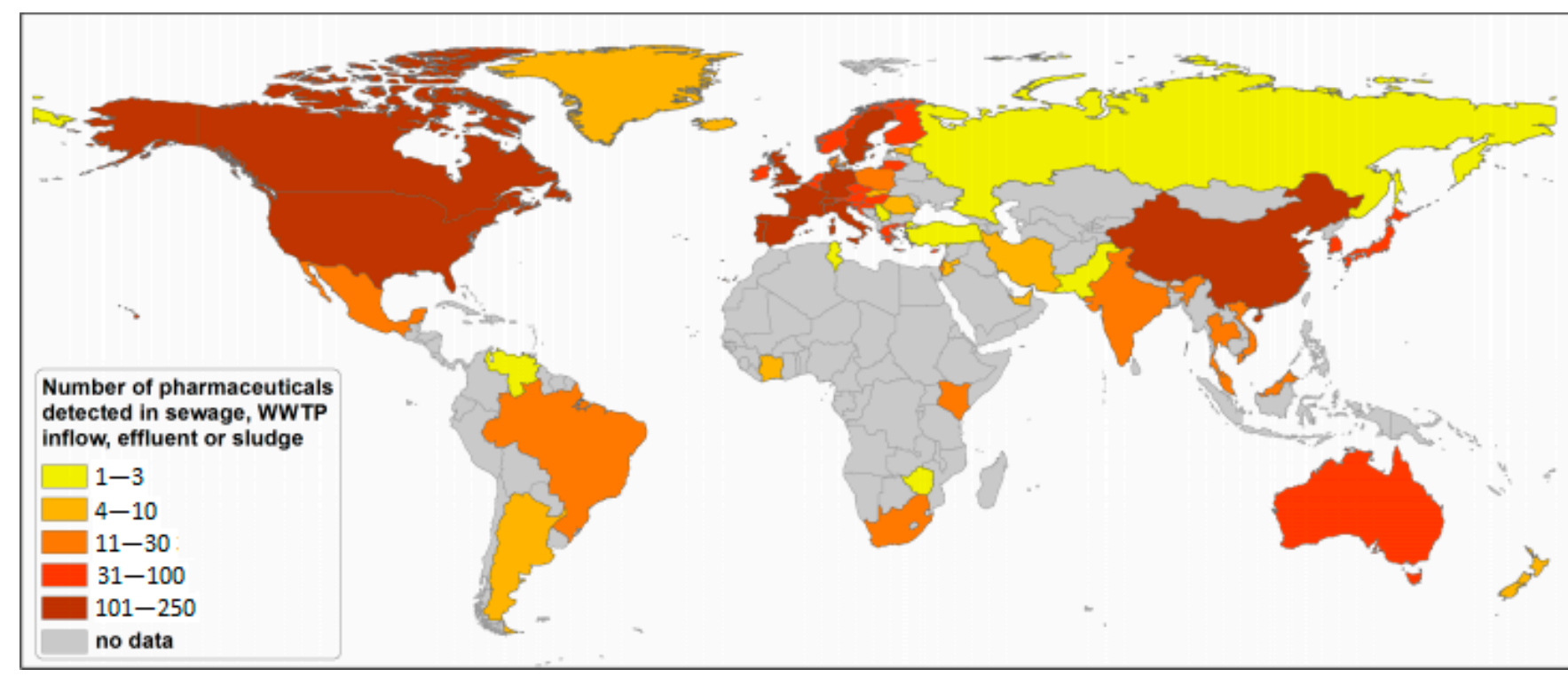

Figure 1. Number of pharmaceuticals detected in sewage, WWTPs' inflow, effluent, and sludge by country [21]. Reproduction license secured from Wiley.

Another type of CECs, non-steroidal anti-inflammatory drugs (NSAIDs), are routinely detected in aquatic ecosystems, due to their wide availability and use as over-the-counter drugs. Regarding African wastewater, several studies confirmed the occurrence of NSAIDS including naproxen, ibuprofen, diclofenac and ketoprofen in WWTPs' effluents, with, for example, concentrations of $20.4 \mu \mathrm{g} / \mathrm{L}$ of naproxen in South Africa [23], 8.02-43.22 $\mu \mathrm{g} / \mathrm{L}$ of ibuprofen in Tunisia [24], and $1.6 \mu \mathrm{g} / \mathrm{L}$ of diclofenac in Algeria [25].

Overall, as far as NSAIDs are concerned, and based on the previously reported studies and others [26-28], ibuprofen seems to be one of the most frequently detected NSAIDs in African wastewater. As a consequence, and due to the inefficiency of WWTPs in removing such pharmaceutical drugs, traces of ibuprofen, paracetamol, and other NSAIDs have been detected in African rivers in South Africa and Nairobi River basin in Kenya [29,30].

Regarding wastewater decontamination, the efficacy of activated sludge-based wastewater treatment to remove CECs is under increased scrutiny by researchers all over the world [31,32]. However, the applied technologies in WWTPs differ from country to country and their efficiency can be compromised with the aging of such facilities and the harsh or fluctuating weather conditions in certain regions. In Africa, most wastewater treatment procedures are based on natural systems such as wastewater stabilization ponds and trickling filters [33]. Hence, due the mitigated depollution ability of such systems (unless correctly designed, operated and maintained), conventional and emerging pollutants can be discharged into water bodies that can be used as drinking water sources, which makes the related R\&D effort an urgent task for African researchers.

\section{Risk Assessment and Impacts of Waterborne CECs on the Environment and Human Health}

For many decades, CECs have been entering aquatic environments regularly through discharged WWTP effluents, industrial wastewaters, agricultural runoff, and municipal landfill leachates. Consequently, aquatic species (fauna and flora) are being continuously exposed to these contaminants of emerging concern, especially organisms that can bioconcentrate and bio-accumulate significant amounts of these CECs to concentrations several times higher than in the water body they live in [34,35].

Globally, several assessment studies conducted in Europe, North America and China emphasized the adverse impacts of a wide range of CECs on the environment, especially aquatic ecosystems. EDCs and many pharmaceuticals, which are environmentally per- 
sistent and bioaccumulating compounds, have great potential environment risks when reaching drinking water supplies or through the food chain [36-38].

For instance, it was revealed that the exposure to diclofenac, a NSAID drug, led to the near-extinction of vultures in the Indian subcontinent. The cause was that the birds were feeding on the carcasses of cattle treated with this drug [39]. In aquatic ecosystems, diclofenac, which is widely detected in African wastewater effluents [26,27], is suspected to cause damage to the inner organs in many fish species $[40,41]$ and sharp declines in the populations of certain fish species due to the feminization of male fish [42]. The same adverse phenomenon, along with reduced fecundity, was also reported for fish species exposed to metformin, an anti-diabetes drug [43]. Such proven adverse eco-toxicological effects on local fish populations provide strong reasons for African researchers to examine such CECs-related issues, especially in African regions with poor sanitation systems or in densely populated areas.

Regarding the assessment of CECs' impacts on the aquatic environment in Africa, interesting studies, although few in number compared to the ones conducted in other continents, presented valuable results. In South Africa, a research team from the University of the Western Cape, Cape Town, investigated the impact of this issue by attempting to accurately analyze the concentrations of fifteen CECs (pharmaceuticals, personal care product, perfluoroalkyl and endocrine disrupting compounds) in different fish samples [44]. The contaminants were selected according to their high annual consumption, their stability and poor elimination during wastewater treatment, along with concerns about adverse effects on human and aquatic organisms. The results revealed that perfluorodecanoic acid (20.1-179.2 ng/g), perfluorononanoic acid (21.2-114.0 ng/g), and perfluoroheptanoic acid (40.1-138.3 ng/g) were the most predominant among the perfluorinated compounds. Moreover, diclofenac was reported to have the highest concentration in the investigated edible fish species out of all the pharmaceuticals detected (551.8-1812 ng/g). As for the risk assessment, the authors reported values above 0.5 and 1.0, respectively, for acute and chronic risk, thus highlighting high health risk to the pelagic fish, aquatic organisms and to humans via the food chain.

In Egypt, a nationwide survey of several CECs in water sources, including bisphenol A (BPA), methylparaben, ethylparaben, propylparaben, butylparaben, and o-phenylphenol, was conducted, along with an assessment of the impacts of the measured concentrations on the aquatic organisms and human health [45]. The results showed that, on the one hand, BPA, methylparaben, propylparaben, and butylparaben were frequently detected in the investigated source and drinking waters. To illustrate the alarming level of the registered data, the authors reported that the highest concentrations of BPA and methylparaben in source water, and those of BPA and methylparaben, propylparaben, and butylparaben in drinking water, were the highest in the world. Regarding the environmental risk assessment, it was showed that among the studied EDCs, BPA presented the highest risk to the aquatic organisms, while human health risks of the exposure to BPA via the consumption of drinking water were at safe levels.

In Nigeria, a research study published in 2020 investigated the distribution and bioaccumulation issues EDCs in Lagos Lagoon as the final sink accumulating and transporting numerous chemicals such as octylphenol (OP), nonylphenol (NP) and BPA [46]. In this study, water and sediment samples were collected at nine locations on the lagoon, along with five different species of fishes. It was observed that BPA was not detected in all the collected water samples. However, the concentrations of NP and OP reached up to $102 \mathrm{ng} / \mathrm{L}$ and $127 \mathrm{ng} / \mathrm{L}$, respectively. In the sediment samples, the EDCs were substantially detected at concentrations reaching up to $5.1 \mu \mathrm{g} / \mathrm{g}$ for BPA, $1.9 \mu \mathrm{g} / \mathrm{g}$ for NP, and $2.5 \mu \mathrm{g} / \mathrm{g}$ for OP. In the fish samples, the highest concentrations were reported at around $1139 \mathrm{ng} / \mathrm{g}$ for BPA, $476 \mathrm{ng} / \mathrm{g}$ for NP, and $643 \mathrm{ng} / \mathrm{g}$ for OP. Such results confirm the bioaccumulation character of the studied EDCs in the Lagos lagoon biota, which can have detrimental effects on other organisms across the food chain. 
Globally, many researchers paid special attention to emerging risks associated with natural and synthetic steroid hormones related to their endocrine-disrupting activities observed in receiving surface waters $[47,48]$. In a related joint South African and Canadian study, the estrogenicity and anti-estrogenicity of EDCs in WWTPs' influents and effluents were assessed using recombinant yeast estrogen receptor binding assays [49]. Thus, seasonal and daily variations were monitored at ten South African WWTPs, as well as the river streams located upstream and downstream of the WWTWs. This comparative analysis was carried out with the objective of assessing potential adverse health risks associated with the measured estrogenic concentrations.

Furthermore, the influence of compounds that may antagonize estrogen-mediated receptor binding (anti-estrogens) in the bioassay was also investigated to further elucidate potential endocrine disrupting risks that WWTP effluents might pose on receiving surface waters. The main results revealed that despite the fact that WWTPs managed to substantially reduce this EDCs menace ( $C f$. Figure 2), the abatement efficiencies tended to vary from one season to another and from a set of locations to another.
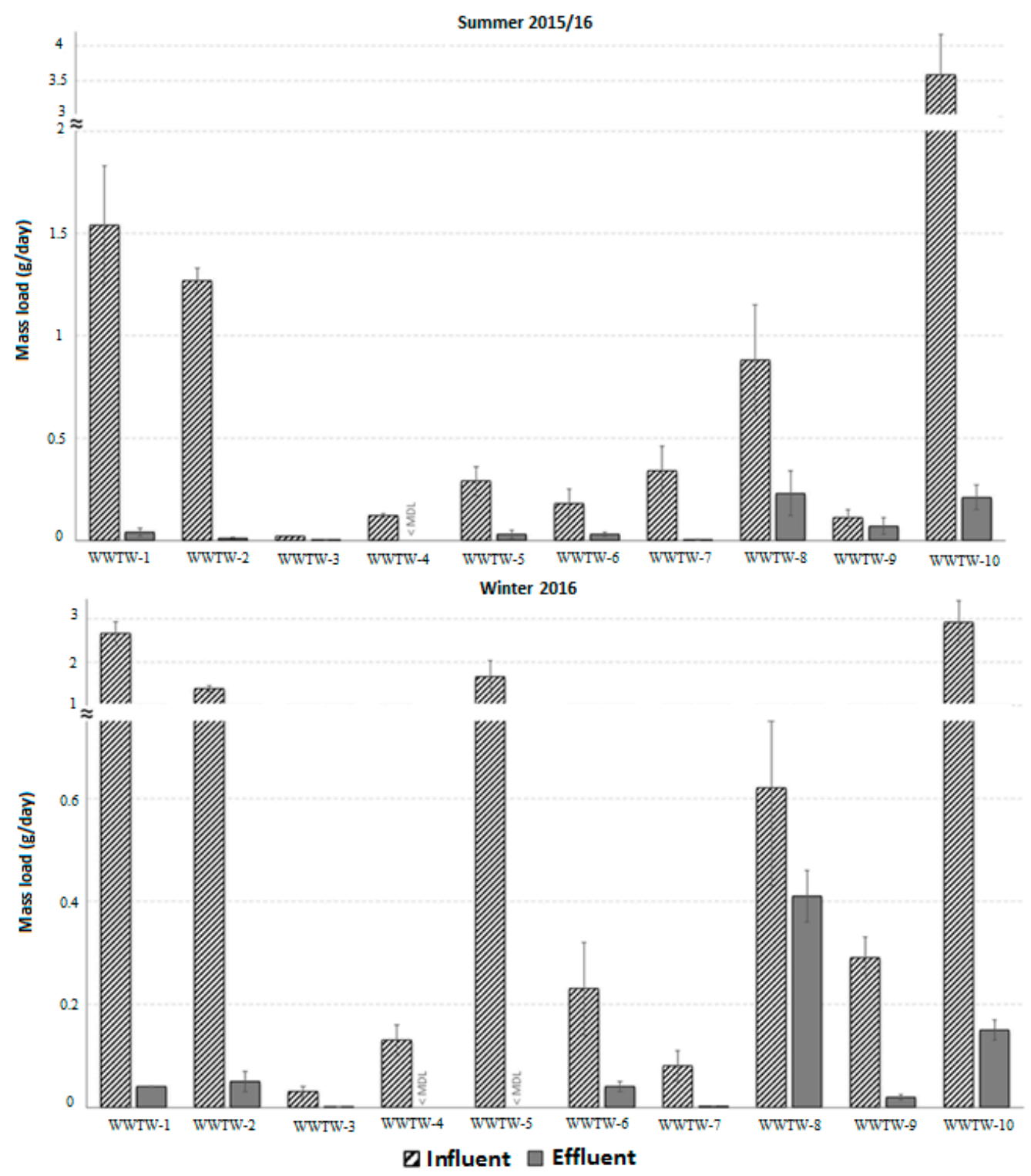

Figure 2. Mass load (g/day) of estrogen equivalent concentrations measured using the yeast estrogen screen for the various WWTPs during sampling campaigns in summer 2015/16 and winter 2016 [49]. Reproduction license secured from Elsevier. 
The reported reasons for such variations were higher weekday/weekend variations for WWTPs receiving wastewater from domestic sources and the amount of estrogenic EDC loads being directly influenced by the ongoing connection of more households to the sewage systems. In terms of season, the variations are linked to the differences in the influx of wastewater at the WWTPs, variable rainfall, and large runoff surges. The study also showed that concentrations in some treated effluent and river water samples were above effect-based trigger values, thus posing an endocrine-disrupting risk.

\section{Removal Technologies Targeting CECs}

The efficiency of contaminants of emerging concern removal depends on the treatment methods and the chemical characteristics of each contaminant, as well as the characteristics of the wastewater treatment plants. Several pharmaceuticals are not removed from wastewater during the treatment processes. This inefficiency depends on the wastewater treatment plant's design, and can also be associated with the desorption phenomenon of CECs from the particulate matter during the treatment process. Other processes may take place during treatment, such as biotransformation/biodegradation, and abiotic elimination by adsorption to the sludge.

For instance, for the case of pharmaceuticals, it was reported that several factors including physico-chemical properties of targeted compounds, and operating conditions of the processes in the WWTPs, did influence the removal efficiency of pharmaceuticals in wastewater [50].

In addition to the application of adsorbents for removal of pharmaceutical contaminants in African waters [51], different technologies for water purification have been explored for various CECs including the use of membrane technology [52], and photoelectrocatalytic water treatment systems [53].

Thus, as shown in Table 1, for some methods, there is a wide variability of removal efficiency for different compounds across various WWTPs in Africa.

Table 1. Selected water treatment technologies targeting emerging pollutants in Africa.

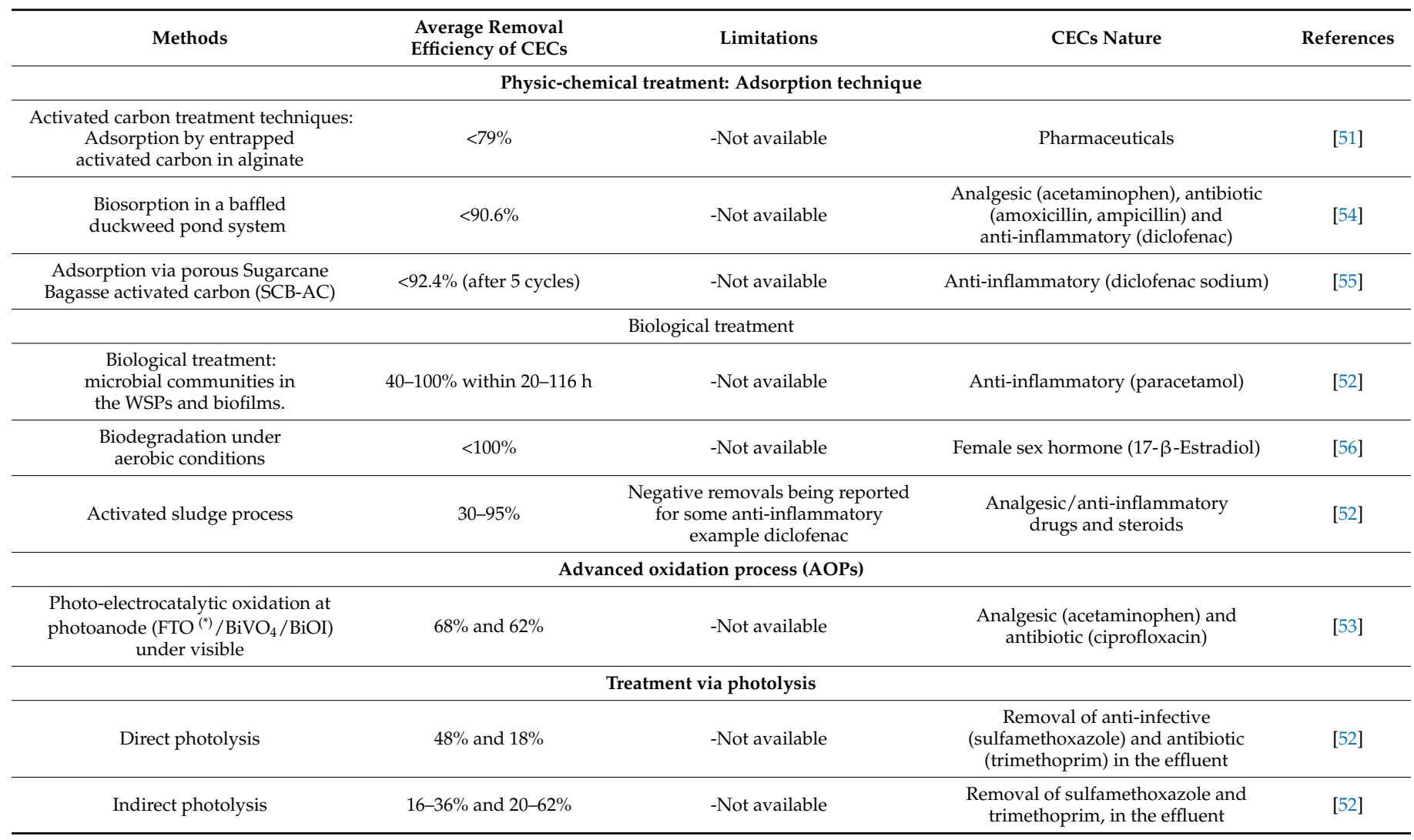


Table 1. Cont.

\begin{tabular}{|c|c|c|c|c|}
\hline Methods & $\begin{array}{l}\text { Average Removal } \\
\text { Efficiency of CECs }\end{array}$ & Limitations & CECs Nature & References \\
\hline \multicolumn{5}{|c|}{ Physical treatment } \\
\hline $\begin{array}{l}\text { Filtration and ultrafiltration } \\
\text { treatment techniques: ceramic } \\
\text { fine ultrafiltration membrane }\end{array}$ & At least $70 \%$ & $\begin{array}{c}\text { Are not commonly accessible } \\
\text { by poor populations in } \\
\text { developing countries }\end{array}$ & $\begin{array}{l}\text { Anti-inflammatory (diclofenac), } \\
\text { calming (diazepam), antibiotic } \\
\text { (erythromycin), and antibacterial } \\
\text { and antifungal (triclosan) }\end{array}$ & [52] \\
\hline \multicolumn{5}{|c|}{ Coupled treatment } \\
\hline Fenton-biological & $<100 \%$ & -Not available & $\begin{array}{l}\text { Antibiotic (chloramphenicol) and } \\
\text { anti-inflammatory (paracetamol, } \\
\text { and diclofenac sodium and } \\
\text { associated by-products) }\end{array}$ & [57] \\
\hline
\end{tabular}

${ }^{(*)}$ Fluorine-doped tin oxide (FTO) coated glass.

Results depicted in Table 1 show the wide variability of removal efficiencies for different compounds across various WWTPs. A reduction of over $95 \%$ was recorded in all WWTPs, which shows that both of the biological processes were efficient in the removal. With respect to wastewater treatment, CECs are partially removed by wastewater stabilization ponds (WSPs) and trickling filter technologies to a similar extent as compared with other techniques (e.g., conventional activated sludge and constructed wetlands), but long hydraulic residence times and thus large surface areas are required. In the African context, numerous adsorbents have been investigated. Various adsorption mechanisms have been reported in different studies for the uptake of pharmaceuticals from water using various adsorbents. In these views, the mode of adsorption was observed to be exclusive for a specific adsorbent directed to a particular pharmaceutical or group of analytes.

\section{Conclusions and Outlook}

This present review presented and analyzed several recent research studies conducted in Africa on the issue of emerging pollutants in the continent's WWTP effluents including the occurrence, fate, assessment of associated risks, and remediation of pharmaceutical drugs, EDS such as synthetic steroid hormones, new biocide molecules, etc. In the beginning, studies related to the assessment of the presence on CECs in wastewater effluents were presented to echo related research efforts in Africa, conducted in a limited number of countries, mostly notably South Africa. Then, the review focused on the research studies reporting the assessment of CECs' impacts on aquatic environment in Africa. Although also limited in number, interesting results were published, and, in some cases, compared to the ones conducted in other continents, which reiterated the urgency and the seriousness of the pollution issue related to CECs. Along with the detection and impact assessments, African researchers carried out several studies to test several technologies for the removal of CECs involving technologies such as adsorption, biological treatment, membrane separation and some advanced oxidation processes.

In the present outlook section, several remarks and important research directions are suggested. First, it has to be highlighted that unlike other studies conducted in North America or Europe, where most households are connected to sewage collection and treatment systems, people in many regions in Africa do not have access to such reliable sanitation systems. In this case, therefore, African scientists cannot only rely on the assessment studies conducted on WWTPs effluents for a consistent assessment of the CECs' contamination issue. Indeed, the human excretions that are directly contaminating water streams can be a significant source of CECs, most notably pharmaceutical drugs, that needs to be taken into consideration. In practice, such research effort is very complicated, and this could be another reason for African scientists to advocate and press for a wider coverage of sanitation systems throughout the continent.

Further, despite the fact that the research effort in Africa on CECs in wastewaters does not reflect the importance of such challenging problems, African scientists need to add another layer of complexity to this issue to properly tackle it in the long term. This involves 
the as-yet unclear impacts of climate change on the fate of CECs in receiving water bodies. The importance of such a new research direction is that it will help in comprehensively understanding and anticipating potential changes in the occurrence and fate of CECs as recalcitrant waterborne pollutants, from their emissions (household and industrial wastes) until their discharges into the environment, and the complex interaction scenarios with the fauna and flora, themselves susceptible to potential climate change impacts.

From an analytical perspective, along with advanced instrumentation that needs to be made available to African researchers to enable analyses at the ppb level, another important matter needs to be highlighted as an essential part in ongoing and future research directions on the CECs issue. In many locations, several pharmaceuticals may occur simultaneously in aquatic environmental ecosystems, thus necessitating new methods and techniques to comprehensively assess the eco-toxicological impacts of low concentrations of mixtures of CECs with potential additive, synergistic or antagonistic modes of action, especially in long-term exposure scenarios.

In general, most African studies related to the assessment of the occurrence and fate of CECs are conducted in urban WWTPs and the receiving water bodies such as rivers and lakes. Thus, most of the research effort is focused on surface water. Considering that groundwater will remain a key component in any water management strategy across Africa, especially with the growing demand for freshwater sources in the continent, few researchers have already investigated this issue [58-60]. Thus, African researchers need to give more attention to the menacing problem of CECs in groundwaters, with a special attention to the shallow wells and groundwater sources which are particularly important as local sources of drinking water, and, as many scientists have reported, are very vulnerable to anthropogenic pollution [61,62].

Overall, African studies on the assessment of the occurrence of CECs in wastewaters and surface waters are expected to increase in number, hopefully with a widespread repartition of the related R\&D effort in numerous African countries. In this regard, however, it is imperative that this research effort does not stop at the occurrence and fate of CECs in wastewaters and aquatic environments. Indeed, CECs and their degradation derivates need to be tracked further downstream to include soils. So far, even at the international level, studies on the full environmental dissemination of several CECs are very limited, understandability due the complexity of their possible interactions, and their sometimescontrasting behavior when CECs, and any other chemical compound for that matter, are channeled from an aqueous media to a solid matrix. For instance, in the commonly applied activated sludge process, CECs are often detected in the generated sludge [63,64]. Worldwide, it is a common practice that dried sludge is used as compost, or often in a compost mixture for soil fertilization. Hence, this is a parallel route for CECs (WWTPs to agricultural fields) that can pose a serious health threat throughout the food chain, and that African scientists need to investigate in their respective countries, simultaneously with the waterborne threat (WWTPS to lakes and rivers).

Last, but not least, and simultaneous to the research effort for detection and analysis. African research needs to speed up the pace in developing and optimizing wastewater treatment systems and technologies tailored to the African context. Research directions in this important topic should focus on the valorization natural resources and wastes to develop locally-sourced and highly-performing adsorbents, ion exchangers, and photocatalysts, within the sustainable paradigm of circular economy. In addition, solar-powered systems need to be given special attention in Africa to make a more efficient use of such renewable and abundant power sources. Considering the various chemical composition and interactions schemes of the CECs, different technologies need to be employed to efficiently deal with such issue. Thus, using WWTPs as a cornerstone in any wastewater treatment strategy, technologies targeting CECs are better suited for tertiary treatments and polishing stages involving technologies such as adsorption, advanced oxidation processes and membrane-based systems, either separately or, in most cases, in an integrated approach to enable the removal and/or degradation of a wider range of CECs. Overall, adopting 
one or more of those wastewater treatment technologies will depend on various conditions related to the socioeconomic specificities of each African community, but overall we need to have a clear and common objective to remove CECs in wastewaters by developing and adopting the most economic and least energy-demanding technologies not only to treat wastewater but also to safely reuse it.

Author Contributions: The authors equally contributed to the present review. All authors have read and agreed to the published version of the manuscript.

Funding: This research received no external funding.

Institutional Review Board Statement: Not applicable.

Informed Consent Statement: Not applicable.

Data Availability Statement: Restrictions apply to the availability of these data. Data was obtained from Elsevier and John Wiley and Sons, and are available at these publishers' websites, with prior permission.

Conflicts of Interest: The authors declare no conflict of interest.

\section{References}

1. Thomaidis, N.S.; Asimakopoulos, A.G.; Bletsou, A.A. Emerging contaminants: A tutorial mini-review. Glob. NEST J. 2012, 14, 72-79.

2. Gago-Ferrero, P.; Krettek, A.; Fischer, S.; Wiberg, K.; Ahrens, L. Suspect screening and regulatory databases: A powerful combination to identify emerging micropollutants. Environ. Sci. Technol. 2018, 52, 6881-6894. [CrossRef] [PubMed]

3. Zhou, S.; Di Paolo, C.; Wu, X.; Shao, Y.; Seiler, T.B.; Hollert, H. Optimization of screening-level risk assessment and priority selection of emerging pollutants-The case of pharmaceuticals in European surface waters. Environ. Int. 2019, 128, 1-10. [CrossRef] [PubMed]

4. Inostroza, P.A.; Massei, R.; Wild, R.; Krauss, M.; Brack, W. Chemical activity and distribution of emerging pollutants: Insights from a multi-compartment analysis of a freshwater system. Environ. Pollut. 2017, 231, 339-347. [CrossRef]

5. Álvarez-Ruiz, R.; Picó, Y. Analysis of emerging and related pollutants in aquatic biota. Trends Environ. Anal. Chem. 2020, 25, e00082. [CrossRef]

6. Ncibi, M.C.; Mahjoub, B.; Mahjoub, O.; Sillanpää, M. Remediation of emerging pollutants in contaminated wastewater and aquatic environments: Biomass-based technologies. CLEAN Soil Air Water 2017, 45, 1700101. [CrossRef]

7. Bellver-Domingo, A.; Fuentes, R.; Hernández-Sancho, F. Shadow prices of emerging pollutants in wastewater treatment plants: Quantification of environmental externalities. J. Environ. Manag. 2017, 203, 439-447. [CrossRef]

8. Assress, H.A.; Nyoni, H.; Mamba, B.B.; Msagati, T.A. Target quantification of azole antifungals and retrospective screening of other emerging pollutants in wastewater effluent using UHPLC-QTOF-MS. Environ. Pollut. 2019, 253, 655-666. [CrossRef]

9. Gurung, K.; Ncibi, M.C.; Thangaraj, S.K.; Jänis, J.; Seyedsalehi, M.; Sillanpää, M. Removal of pharmaceutically active compounds (PhACs) from real membrane bioreactor (MBR) effluents by photocatalytic degradation using composite Ag2O/P-25 photocatalyst. Sep. Purif. Technol. 2019, 215, 317-328. [CrossRef]

10. Gurung, K.; Ncibi, M.C.; Sillanpää, M. Removal and fate of emerging organic micropollutants (EOMs) in municipal wastewater by a pilot-scale membrane bioreactor (MBR) treatment under varying solid retention times. Sci. Total Environ. 2019, 667, 671-680. [CrossRef]

11. Lares, M.; Ncibi, M.C.; Sillanpää, M. Occurrence, identification and removal of microplastic particles and fibers in conventional activated sludge process and advanced MBR technology. Water Res. 2018, 133, 236-246. [CrossRef] [PubMed]

12. Peña-Guzmán, C.; Ulloa-Sánchez, S.; Mora, K.; Helena-Bustos, R.; Lopez-Barrera, E.; Alvarez, J.; Rodriguez-Pinzón, M. Emerging pollutants in the urban water cycle in Latin America: A review of the current literature. J. Environ. Manag. 2019, 237, 408-423. [CrossRef] [PubMed]

13. Montes-Grajales, D.; Fennix-Agudelo, M.; Miranda-Castro, W. Occurrence of personal care products as emerging chemicals of concern in water resources: A review. Sci. Total Environ. 2017, 595, 601-614. [CrossRef] [PubMed]

14. Petrovic, M.; Eljarrat, E.; De Alda, M.L.; Barceló, D. Endocrine disrupting compounds and other emerging contaminants in the environment: A survey on new monitoring strategies and occurrence data. Anal. Bioanal. Chem. 2004, 378, 549-562. [CrossRef] [PubMed]

15. Connolly, L. Endocrine-disrupting chemicals: Origins, fates and transmission into the food chain. In Endocrine-Disrupting Chemicals in Food; Woodhead Publishing: Cambridge, UK, 2009; pp. 103-125.

16. Madikizela, L.M.; Ncube, S.; Chimuka, L. Analysis, occurrence and removal of pharmaceuticals in African water resources: A current status. J. Environ. Manag. 2020, 253, 109741. [CrossRef]

17. Adeleye, A.P. Perfluorinated Compounds, Bishenol a and Acetaminophen in Selected Waste Water Treatment Plants in and Around Cape Town, South Africa. Ph.D. Thesis, Cape Peninsula University of Technology, Cape Town, South Africa, 2016. 
18. Fekadu, S.; Alemayehu, E.; Dewil, R.; Van der Bruggen, B. Pharmaceuticals in freshwater aquatic environments: A comparison of the African and European challenge. Sci. Total Environ. 2019, 654, 324-337. [CrossRef]

19. Ebele, A.J.; Abdallah, M.A.E.; Harrad, S. Pharmaceuticals and personal care products (PPCPs) in the freshwater aquatic environment. Emerg. Contam. 2017, 3, 1-16. [CrossRef]

20. Madikizela, L.M.; Tavengwa, N.T.; Chimuka, L. Status of pharmaceuticals in African water bodies: Occurrence, removal and analytical methods. J. Environ. Manag. 2017, 193, 211-220. [CrossRef]

21. Aus der Beek, T.; Weber, F.A.; Bergmann, A.; Hickmann, S.; Ebert, I.; Hein, A.; Küster, A. Pharmaceuticals in the environment-Global occurrences and perspectives. Environ. Toxicol. Chem. 2016, 35, 823-835. [CrossRef]

22. Tahrani, L.; Van Loco, J.; Anthonissen, R.; Verschaeve, L.; Ben Mansour, H.; Reyns, T. Identification and risk assessment of human and veterinary antibiotics in the wastewater treatment plants and the adjacent sea in Tunisia. Water Sci. Technol. 2017, 76, 3000-3021. [CrossRef]

23. Amdany, R.; Chimuka, L.; Cukrowska, E. Determination of naproxen, ibuprofen and triclosan in wastewater using the polar organic chemical integrative sampler (POCIS): A laboratory calibration and field application. Water Sa 2014, 40, 407-414. [CrossRef]

24. Khazri, H.; Ben Hassine, S.; Ghorbel-Abid, I.; Kalfat, R.; Trabelsi-Ayadi, M. Presence of carbamazepine, naproxen, and ibuprofen in wastewater from northern Tunisia. Environ. Forensics 2019, 20, 121-128. [CrossRef]

25. Kermia, A.E.B.; Fouial-Djebbar, D.; Trari, M. Occurrence, fate and removal efficiencies of pharmaceuticals in wastewater treatment plants (WWTPs) discharging in the coastal environment of Algiers. Comptes Rendus Chim. 2016, 19, 963-970. [CrossRef]

26. Ngubane, N.P.; Naicker, D.; Ncube, S.; Chimuka, L.; Madikizela, L.M. Determination of naproxen, diclofenac and ibuprofen in Umgeni estuary and seawater: A case of northern Durban in KwaZulu-Natal Province of South Africa. Reg. Stud. Mar. Sci. 2019, 29, 100675. [CrossRef]

27. Amos Sibeko, P.; Naicker, D.; Mdluli, P.S.; Madikizela, L.M. Naproxen, ibuprofen, and diclofenac residues in river water, sediments and Eichhornia crassipes of Mbokodweni river in South Africa: An initial screening. Environ. Forensics 2019, 20, 129-138. [CrossRef]

28. Germaine, A.O.; Joseph, K.S. Seasonal occurrence of ibuprofen in sediment, water, and biota in river owena and ogbese, and its ecological risk assessment. Ann. Sci. Technol. 2020, 5, 11-19. [CrossRef]

29. Ngumba, E.; Gachanja, A.; Tuhkanen, T. Occurrence of selected antibiotics and antiretroviral drugs in Nairobi River Basin, Kenya. Sci. Total Environ. 2016, 539, 206-213. [CrossRef]

30. Mhuka, V.; Dube, S.; Nindi, M.M. Occurrence of pharmaceutical and personal care products (PPCPs) in wastewater and receiving waters in South Africa using LC-Orbitrap ${ }^{\mathrm{TM}}$ MS. Emerg. Contam. 2020, 6, 250-258. [CrossRef]

31. Deblonde, T.; Cossu-Leguille, C.; Hartemann, P. Emerging pollutants in wastewater: A review of the literature. Int. J. Hyg. Environ. Health 2011, 214, 442-448. [CrossRef]

32. Mailler, R.; Gasperi, J.; Coquet, Y.; Buleté, A.; Vulliet, E.; Deshayes, S.; Caupos, E. Removal of a wide range of emerging pollutants from wastewater treatment plant discharges by micro-grain activated carbon in fluidized bed as tertiary treatment at large pilot scale. Sci. Total Environ. 2016, 542, 983-996. [CrossRef]

33. Faleye, A.C.; Adegoke, A.A.; Ramluckan, K.; Fick, J.; Bux, F.; Stenström, T.A. Concentration and reduction of antibiotic residues in selected wastewater treatment plants and receiving waterbodies in Durban, South Africa. Sci. Total Environ. 2019, 678, 10-20. [CrossRef] [PubMed]

34. Choo, G.; Wang, W.; Cho, H.S.; Kim, K.; Park, K.; Oh, J.E. Legacy and emerging persistent organic pollutants in the freshwater system: Relative distribution, contamination trends, and bioaccumulation. Environ. Int. 2020, 135, 105377. [CrossRef] [PubMed]

35. Previšić, A.; Rožman, M.; Mor, J.R.; Acuña, V.; Serra-Compte, A.; Petrović, M.; Sabater, S. Aquatic macroinvertebrates under stress: Bioaccumulation of emerging contaminants and metabolomics implications. Sci. Total Environ. 2020, 704, 135333. [CrossRef] [PubMed]

36. Henderson, A.; Ng, B.; Landeweer, S.; Quinete, N.; Gardinali, P. Assessment of sucralose, caffeine and acetaminophen as anthropogenic tracers in aquatic systems across Florida. Bull. Environ. Contam. Toxicol. 2020, 105, 351-357. [CrossRef]

37. Ribeiro, E.; Ladeira, C.; Viegas, S. EDCs mixtures: A stealthy hazard for human health? Toxics 2017, 5, 5. [CrossRef]

38. Liu, D.; Wu, S.; Xu, H.; Zhang, Q.; Zhang, S.; Shi, L.; Cheng, J. Distribution and bioaccumulation of endocrine disrupting chemicals in water, sediment and fishes in a shallow Chinese freshwater lake: Implications for ecological and human health risks. Ecotoxicol. Environ. Saf. 2017, 140, 222-229.

39. Green, R.E.; Newton, I.A.N.; Shultz, S.; Cunningham, A.A.; Gilbert, M.; Pain, D.J.; Prakash, V. Diclofenac poisoning as a cause of vulture population declines across the Indian subcontinent. J. Appl. Ecol. 2004, 41, 793-800. [CrossRef]

40. Horie, Y.; Yamagishi, T.; Yagi, A.; Shintaku, Y.; Iguchi, T.; Tatarazako, N. The non-steroidal anti-inflammatory drug diclofenac sodium induces abnormal embryogenesis and delayed lethal effects in early life stage zebrafish (Danio rerio). J. Appl. Toxicol. 2019, 39, 622-629. [CrossRef]

41. Bio, S.; Nunes, B. Acute effects of diclofenac on zebrafish: Indications of oxidative effects and damages at environmentally realistic levels of exposure. Environ. Toxicol. Pharmacol. 2020, 78, 103394. [CrossRef]

42. Mehinto, A.C.; Hill, E.M.; Tyler, C.R. Uptake and biological effects of environmentally relevant concentrations of the nonsteroidal anti-inflammatory pharmaceutical diclofenac in rainbow trout (Oncorhynchus mykiss). Environ. Sci. Technol. 2010, 44, $2176-2182$. [CrossRef] 
43. Niemuth, N.J.; Klaper, R.D. Emerging wastewater contaminant metformin causes intersex and reduced fecundity in fish. Chemosphere 2015, 135, 38-45. [CrossRef] [PubMed]

44. Ojemaye, C.Y.; Petrik, L. Occurrences, levels and risk assessment studies of emerging pollutants (pharmaceuticals, perfluoroalkyl and endocrine disrupting compounds) in fish samples from Kalk Bay harbour, South Africa. Environ. Pollut. 2019, 252, 562-572. [CrossRef] [PubMed]

45. Radwan, E.K.; Ibrahim, M.B.M.; Adel, A.; Farouk, M. The occurrence and risk assessment of phenolic endocrine-disrupting chemicals in Egypt's drinking and source water. Environ. Sci. Pollut. Res. 2020, 27, 1776-1788. [CrossRef] [PubMed]

46. Adeyi, A.A. Distribution and bioaccumulation of endocrine disrupting chemicals (EDCS) in Lagos Lagoon water, sediment and fish. IFE J. Sci. 2020, 22, 057-074.

47. Thrupp, T.J.; Runnalls, T.J.; Scholze, M.; Kugathas, S.; Kortenkamp, A.; Sumpter, J.P. The consequences of exposure to mixtures of chemicals: Something from 'nothing'and 'a lot from a little'when fish are exposed to steroid hormones. Sci. Total Environ. 2018, 619, 1482-1492. [CrossRef]

48. Houtman, C.J.; Ten Broek, R.; van Oorschot, Y.; Kloes, D.; van der Oost, R.; Rosielle, M.; Lamoree, M.H. High resolution effectdirected analysis of steroid hormone (ant) agonists in surface and wastewater quality monitoring. Environ. Toxicol. Pharmacol. 2020, 80, 103460. [CrossRef]

49. Archer, E.; Wolfaardt, G.M.; van Wyk, J.H.; van Blerk, N. Investigating (anti) estrogenic activities within South African wastewater and receiving surface waters: Implication for reliable monitoring. Environ. Pollut. 2020, 263, 114424. [CrossRef]

50. Moslah, B.; Hapeshi, E.; Jrad, A.; Fatta-Kassinos, D.; Hedhili, A. Pharmaceuticals and illicit drugs in wastewater samples in north-eastern Tunisia. Environ. Sci. Pollut. Res. 2018, 25, 18226-18241. [CrossRef]

51. Abdel-Gawad, S.A.; Abd El-Aziz, H.M. Removal of pharmaceuticals from aqueous medium using entrapped activated carbon in alginate. Air Soil Water Res. 2019, 12, 1178622119848761. [CrossRef]

52. K'oreje, K.O.; Okoth, M.; Van Langenhove, H.; Demeestere, K. Occurrence and treatment of contaminants of emerging concern in the African aquatic environment: Literature review and a look ahead. J. Environ. Manag. 2020, 254, 109752. [CrossRef]

53. Orimolade, B.O.; Koiki, B.A.; Peleyeju, G.M.; Arotiba, O.A. Visible light driven photoelectrocatalysis on a FTO/BiVO4/BiOI anode for water treatment involving emerging pharmaceutical pollutants. Electrochim. Acta 2019, 307, 285-292. [CrossRef]

54. Bassuney, D.; Tawfik, A. Baffled duckweed pond system for treatment of agricultural drainage water containing pharmaceuticals. Int. J. Phytoremediat. 2017, 19, 774-780. [CrossRef] [PubMed]

55. El Naga, A.O.A.; El Saied, M.; Shaban, S.A.; El Kady, F.Y. Fast removal of diclofenac sodium from aqueous solution using sugar cane bagasse-derived activated carbon. J. Mol. Liq. 2019, 285, 9-19. [CrossRef]

56. Khattab, R.A.; Elnwishy, N.; Hannora, A.; Mattiasson, B.; Omran, H.; Alharbi, O.M.L.; Ali, I. Biodegradation of 17- $\beta$-estradiol in water. Int. J. Environ. Sci. Technol. 2019, 16, 4935-4944. [CrossRef]

57. Badawy, M.I.; Wahaab, R.A.; El-Kalliny, A.S. Fenton-biological treatment processes for the removal of some pharmaceuticals from industrial wastewater. J. Hazard. Mater. 2009, 167, 567-574. [CrossRef] [PubMed]

58. Sorensen, J.P.R.; Lapworth, D.J.; Nkhuwa, D.C.W.; Stuart, M.E.; Gooddy, D.C.; Bell, R.A.; Pedley, S. Emerging contaminants in urban groundwater sources in Africa. Water Res. 2015, 72, 51-63. [CrossRef] [PubMed]

59. K'oreje, K.O.; Vergeynst, L.; Ombaka, D.; De Wispelaere, P.; Okoth, M.; Van Langenhove, H.; Demeestere, K. Occurrence patterns of pharmaceutical residues in wastewater, surface water and groundwater of Nairobi and Kisumu city, Kenya. Chemosphere 2016, 149, 238-244. [CrossRef]

60. Pinasseau, L.; Wiest, L.; Fildier, A.; Volatier, L.; Fones, G.R.; Mills, G.A.; Vulliet, E. Use of passive sampling and high-resolution mass spectrometry using a suspect screening approach to characterise emerging pollutants in contaminated groundwater and runoff. Sci. Total Environ. 2019, 672, 253-263. [CrossRef]

61. Hunter, P.R.; MacDonald, A.M.; Carter, R.C. Water supply and health. PLoS Med. 2010, 7, e1000361. [CrossRef]

62. Lapworth, D.J.; Baran, N.; Stuart, M.E.; Ward, R.S. Emerging organic contaminants in groundwater: A review of sources, fate and occurrence. Environ. Pollut. 2012, 163, 287-303. [CrossRef]

63. Díaz-Cruz, M.S.; García-Galán, M.J.; Guerra, P.; Jelic, A.; Postigo, C.; Eljarrat, E.; Barceló, D. Analysis of selected emerging contaminants in sewage sludge. TrAC Trends Anal. Chem. 2009, 28, 1263-1275. [CrossRef]

64. Fijalkowski, K.; Rorat, A.; Grobelak, A.; Kacprzak, M.J. The presence of contaminations in sewage sludge-The current situation. J. Environ. Manag. 2017, 203, 1126-1136. [CrossRef] [PubMed] 